\title{
STRATEGI PEMASARAN JAMU DI ERA INDUSTRI 4.0
}

\author{
Liana Vivin Wihartanti ${ }^{1 *}$, Ramadhan Prasetya Wibawa ${ }^{2}$, Ihtiari Prasetyaningrum ${ }^{3}$, \\ Isharijadi $^{4}$ \\ ${ }^{1 *}$ Universitas PGRI Madiun \\ lianavivin@unipma.ac.id \\ ${ }^{2,3,4}$ Universitas PGRI Madiun \\ ${ }^{2}$ ramadhan@unipma.ac.id, ${ }^{3}$ Ihtiari.Prasetya@unipma.ac.id, ${ }^{4}$ isharijadi@unipma.ac.id
}

\begin{abstract}
ABSTRAK
Di era industri 4.0 inovasi produk merupakan ciri pengembangan produk itu kearah lebih maju, dan strategi pemasaran sebagai pendorong untuk meningkatkan nilai jual produk unggulan yang mencerminkan ciri khas produk unggul yang ada di suatu daerah. Dalam pelaksanaan kegiatan pengabdian masyarakat dilaksanakan dengan empat tahapan. Tujuan kegiatan pengabdian masyarakat adalah produk jamu Joketro dikenal oleh masyarakat sebagai produk unggulan, pangsa pasar target penjual jamu lebih luas dengan adanya kemasan baru yang lebih higienis, dan untuk meningkatkan pendapatan lokal di daerah tersebut. Mitra yang terlibat dalam kegiatan pengabdian masyarakat ini diantaranya: Perangkat Desa Joketro, Ibu-Ibu PKK, dan Penjual Jamu Tradisioanal. Hasil dari pengabdian masyarakat adalah pembentukan kelompok jamu penting dalam membantu dalam memperkuat kelompok dan memperluas jaringan pemasaran.
\end{abstract}

Kata Kunci: jamu tradisional; pemasaran; industri 4.0

\begin{abstract}
In the industrial era 4.0, product innovation is a hallmark of product development in a more advanced direction, and marketing strategy as a driving force to increase the selling value of superior products that reflect the characteristics of superior products in an area. The implementation of community service activities is carried out in four stages. The purpose of community service activities is that the joketro herbal product is known by the public as a superior product, the target market for herbal medicine sellers is wider with the new, more hygienic packaging, and to increase local income in the area. Partners involved in this community service activity include: Joketro Village Officials, PKK Mothers, and Traditional Herbal Medicine Sellers. The result of community service is the formation of an important herbal medicine group in helping to strengthen the group and expand the marketing network.
\end{abstract}

Keywords: traditional herbal medicine, marketing, industry 4.0 


\section{PENDAHULUAN}

Indonesia merupakan negara kepulauan yang terdiri atas 17.000 pulau lebih yang tersebar dari Sabang sampai Merauke. Di Indonesia tanaman obat merupakan salah satu jenis tanaman yang telah digunakan secara turun-temurun sejak ratusan tahun silam sebagai warisan nenek moyang. Keanekaragaman tumbuhan, hewan, dan bahan mineral yang ada di Indonesia merupakan salah satu modal untuk mengembangkan perekonomian rakyat. Jamu sebagai produk asli Indonesia yang dikenal hingga mancanegara (Neubauer, 2012). Jamu tradisional adalah salah satu produk warisan budaya bangsa yang perlu dilestarikan. Jamu pada masa kerajaan digunakan sebagai penyembuh penyakit, penjaga kebugaran, menjaga kecantikan (Prabawani, 2017). Minuman jamu tidak saja unik tapi juga memiliki khasiat yang baik untuk kesehatan. Oleh karena itu pengembangan pasar dan usaha jamu sangat potensial. Saat ini pengrajin jamu sebagian besar menjalankan usahanya secara tradisional. Jamu dijual dalam bentuk cair (langsung diminum) atau dikenal dengan jamu gendong, instan, bahan peras, rajangan yang dijual dengan cara menetap di pasar, warung, berkeliling dengan sepeda, berjalan kaki ataupun dengan gerobag keliling. Pada masa sekarang jamu dikonsumsi sebagai pengobatan komplementer dan alternatif (Nissen \& Evans, 2012).

Daerah Desa Joketro terkenal akan jamu gendongnya hal dapat dilihat dari mayoritas penduduknya bermata pencaharian selain petani adalah pengrajin jamu gendong yang dijajakan secara keliling disekitar kabupaten Magetan dan sekitarnya. Cita rasa jamu yang dibuat oleh pengrajin jamu gendong memiliki ciri khas tersendiri hal inilah yang menjadikan jamu gendong di Desa Joketro banyak digemari para pecinta jamu. Resep yang dari nenek moyang yang turun temurunlah yang menjadikan ciri khas rasa jamu gendong Joketro beda dengan jamu yang dijual dipasaran pada umumnya.

Daerah Desa Joketro Kecamatan Parang Kabupaten Magetan merupakan wilayah yang terdapat di bukit lereng gunung lawu. Di sekitar wilayah desa terdapat banyak area persawahan sehingga rata - rata mata pencarian warga sekitar Joketro adalah petani. Desa Joketro memiliki 4 (empat) dusun yaitu Dusun Joketro, Dusun Ngasinan, Dusun Lebak, dan Dusun Lempong Desa Joketro memiliki penduduk kurang lebih 3228 orang dengan batas wilayah sebelah Utara : Desa Pendem, Timur : Desa Krajan, Selatan: Desa 
Krajan, Barat : Kel. Parang. Di Desa joketro dipimpin oleh Kepala Desa yang bernama Marjoko. Di Desa Joketro terdapat diantaranya kelompok usaha Jamu Gendong bernama kelompok Usaha Joketro dan Kelompok Usaha Lempong. Berikut saya sampaikan profil Desa Joketro.

Pengrajin jamu gendong yang ada di Desa Joketro Kabupaten Magetan umumnya adalah Ibu- Ibu dengan tingkat pendidikan rata-rata sekolah dasar dan ekonomi yang masih minim. Para pengrajin jamu tersebut menggunakan ramuan tradisional yang digunakan oleh para leluhurnya dalam meracik jamu. Usaha yang mereka geluti hanya berkisar pada membuat jamu gendong dengan tingkat produksi yang sangat rendah yaitu hanya 2 botol atau 1,5 liter untuk beberapa produk. Produk yang mereka buat diantaranya beras kencur, kunir asem, cebe puyang, kunci suruh dan kunci pepet, temulawak, paitan. Proses atau metode pembuatan jamu yang kurang memperhatikan aspek higienis dan mutu jamu. Bentuk jamu yang dibuat belum beragam dan tidak memungkinkan untuk disimpan dalam waktu lama. Menurut Syafi'i (2020) Apabila dievaluasi produksi itu sebenarnya masih bisa ditingkatkan dalam aspek jumlah maupun diversifikasi produk yang mampu dibuat. Diversifikasi produk herbal sangat berpengaruh dalam pemasaran karena segmen pasar produk herbal memiliki minat yang berbeda-beda. Produk juga belum memiliki sertifikat halal dari MUI serta belum memiliki Izin Usaha Resmi. Menurut Syafi'i (2020) untuk meningkatkan hasil produksi jamu tradisional ada dua point yaitu pengemasan dan pemasaran

Permasalahan pada bidang produksi yang ada di Desa Joketro adalah kurangnya pengetahuan warga terkait dengan pemanfaatan Teknologi Industri 4.0. Disana mereka menjual jamu dengan cara digendong, dan harganya pun masih tergolong murah. Menurut Natadjaja et al., (2013) penyajian jamu masih tergolong monoton dalam hal kemasan, terutama ditinjau dari aspek visual. Oleh karena itu perlu suatu strategi agar pemasaran jamu Desa Joketro mampu diterima menjadi produk unggulan khas dari Desa Joketro dan menjadi produk yang diminati masyarakat. 


\section{METODE}

Kegiatan pengabdian masyarakat ini dilaksanakan di Balai Desa Joketro pada tanggal 2 Maret 2020. Untuk mengatasi permasalahan di atas metode yang dilaksanakan untuk mengatasi melalui kegiatan 1) Observasi dan Koordinasi dengan Perangkat Desa Joketro; 2) Sosialisasi kepada masyarakat perlunya dibentuk kelompok Jamu di Desa Joketro; 3) Penyuluhan tentang cara mengenalkan jamu tradisonal; 4) Pelatihan pengemasan produk jamu, pemasaran, dan cara meningkatkan penjualan jamu tradisional. Tujuan program pengabdian masyarakat yang kami laksanakan di Desa Joketro tidak lain adalah produk jamu Joketro dikenal oleh masyarakat sebagai produk unggulan, pangsa pasar target penjual jamu lebih luas dengan adanya kemasan baru yang lebih higienis, dan untuk meningkatkan pendapatan lokal di daerah tersebut. Mitra yang terlibat dalam kegiatan pengabdian masyarakat ini diantaranya: Perangkat Desa Joketro, Ibu-Ibu PKK, dan Penjual Jamu Tradisioanal.

\section{HASIL DAN PEMBAHASAN}

Pelaksanaan kegiatan pengabdian masyarakat ini meliputi:

\section{Observasi dan Koordinasi dengan Perangkat Desa}

Kegiatan observasi yang dilakukan dengan melakukan pencarian data terkait dengan produk Jamu yang ada di Desa Joketro, jumlah penjual jamu Joketro, permasalahan yang dihadapi penjual jamu dalam pemasarannya. Konsultasi dengan Perangkat Desa yang ada, selanjutnya mengindentifikasi permasalah untuk diberikan solusi untuk memecahkan masalah tersebut. Koordinasi dengan kepala desa dilakukan untuk memastikan jadwal pelaksanaan kegiatan pengabdian, tempat, dan pihak peserta yang dilibatkan dalam kegiatan tersebut.

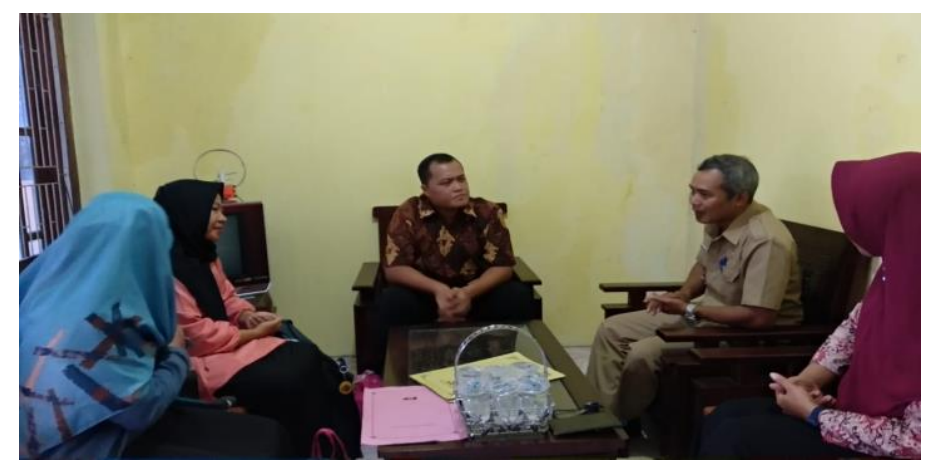

Gambar 1. Koordinasi dengan Kepala Desa 


\section{Sosialisasi Kepada Masyarakat Perlunya Dibentuk Kelompok Jamu Di Desa}

\section{Joketro}

Kegiatan yang pertama dilakukan adalah melakukan sosialisasi langsung di Balai Desa Joketro bahwa pentingnya dibentuk suatu kelompok penjual jamu. Penyampaian materi dengan memberikan motivasi kepada penjual jamu untuk segera membentuk kelompok jamu. Kelompok jamu bisa dalam satu dusun atau langsung satu desa dengan mempertimbangkan juga masukan dari perangkat desa yang ada. Apabila kelompok jamu sudah terbentuk agar disampaikan kepada Kepala Desa siapa saja yang menjadi ketua Jamu di kelompok itu.

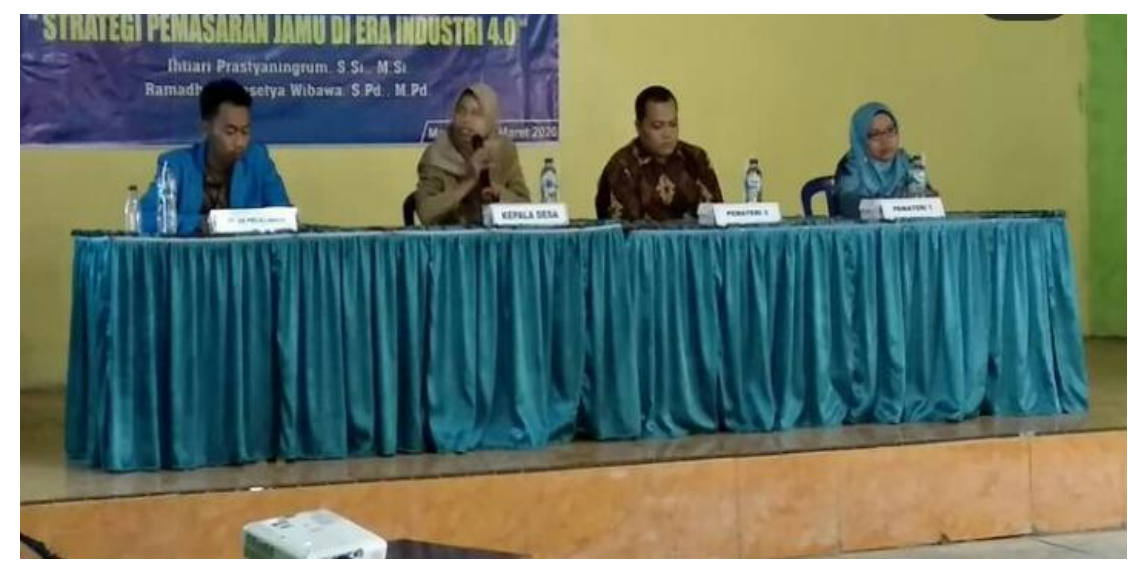

Gambar 2. Sosialisasi Pembentukan Kelompok Jamu Joketro

\section{Penyuluhan Tentang Cara Mengenalkan Jamu Tradisonal}

Kegiatan yang dilakukan agar jamu tradisional dikenal masyarakat adalah mengajak masyarakat Desa Joketro untuk mencintai dahulu tentang pentingnya jamu tradisional untuk kesehatan. Upaya yang kami lakukan adalah mengajak terutama anakanak untuk mencoba mengkonsumsi jamu tradisional sebagai minuman kesehatan dengan dibantu Kepala Desa akan melaksanakan gerakan minum jamu yang diikuti oleh seluruh masyarakat desa. Kegiatan tersebut sekiranya bisa menjadi budaya bagi desa untuk selanjutnya juga diinformasikan kepada masyarakat diluar desa dengan memposting kegiatan rutin itu pada media sosial agar memberikan wawasan luas bagi masyarakat. 


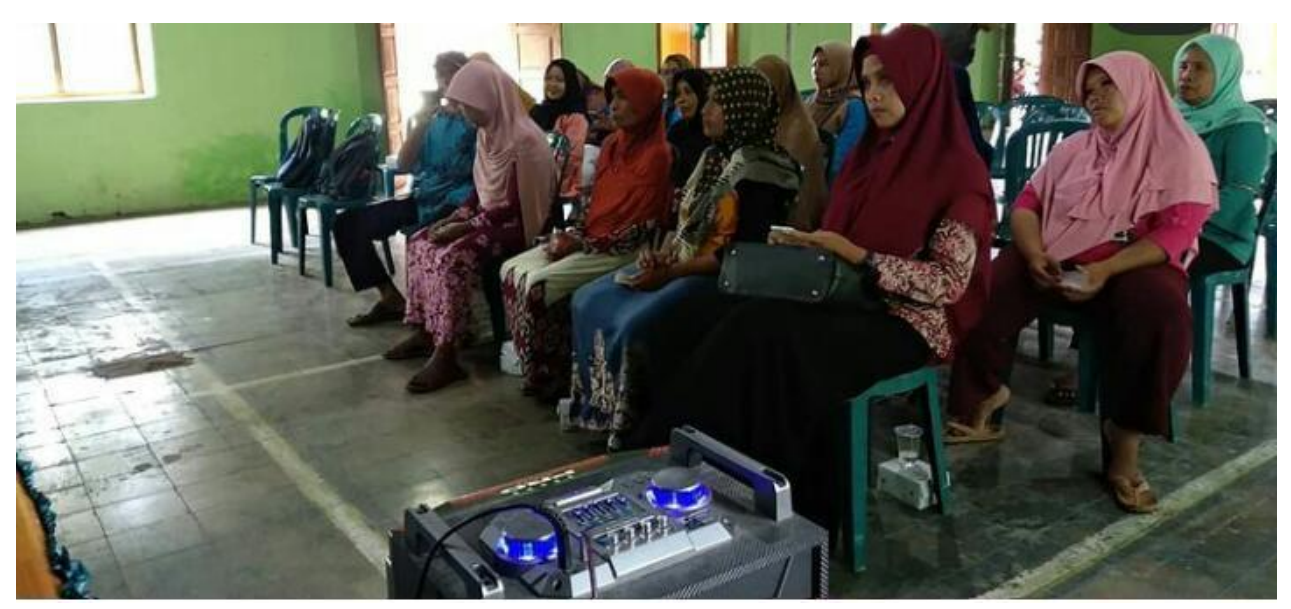

Gambar 3. Penyuluhan Cara Pengenalan Jamu Joketro

\section{Pelatihan Pengemasan Jamu Joketro}

Pemasaran Jamu Joketro saat ini masih dikatakan sangat konvensional. Pemasaran hanya dilakukan berkeliling kampung. Jamu dijual dalam wadah plastik dengan harga Rp 1.000,00 per bungkus. Dalam sosialisasi ini kami coba berikan model kemasan menggunakan botol plastik yang kita beri label. Dari sini kami mulai memberikan pemahaman tentang pemasaran jamu di era RI 4.0, dimana kemasan harus lebih modern sehingga dapat dinikmati berbagai kalangan masyarakat.

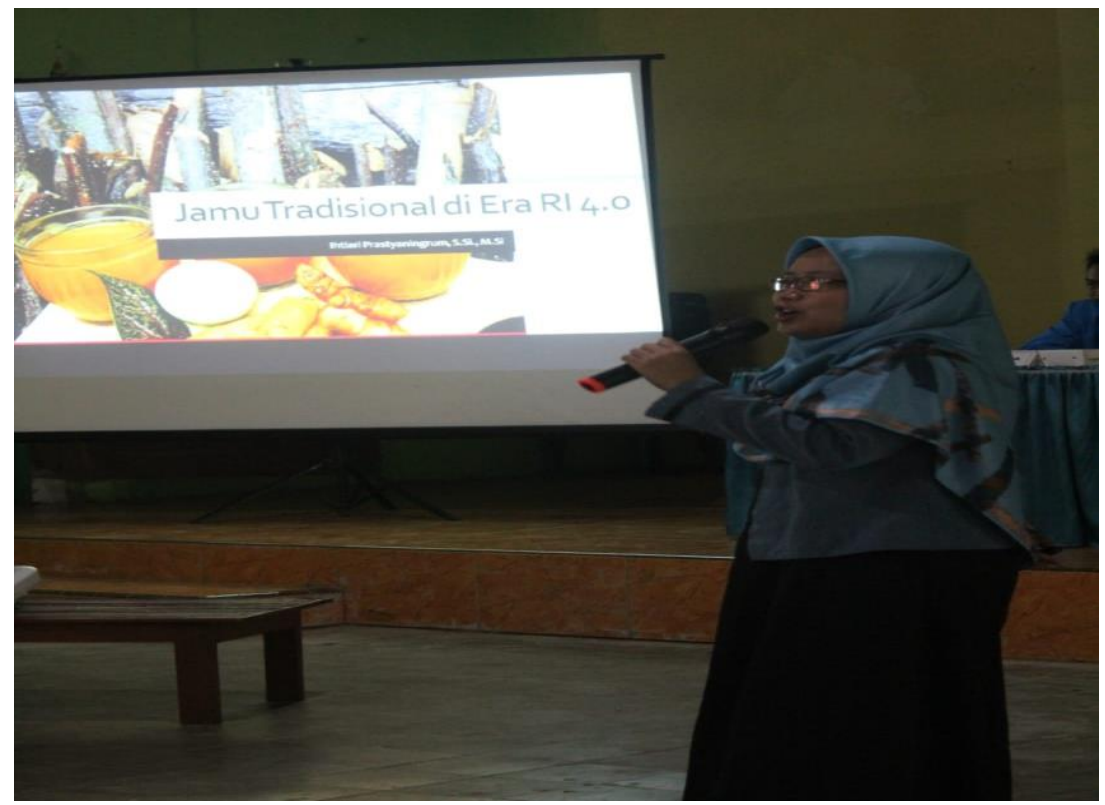

Gambar 4. Pelatihan Pengemasan Produk Jamu 


\section{Pelatihan Pemasaran}

Agar Jamu Joketro lebih dikenal luas oleh masyarakat, maka kami coba kenalkan model pemasaran online. Upaya yang sudah dilakukan tim pengabdian masyarakat didampingi salah satu warga masyarakat desa Joketro dengan memasarkan Jamu Joketro pada kegiatan Car Free Day setiap Hari Minggu di Kota Madiun, dan mengikuti Bazar. Tentu saja hal ini harus didukung dengan model pengemasan produk yang memadai. Kedepannya kami melibatkan pemuda karang taruna dan Ibu-ibu PKK untuk proses pemasaran. Pemanfaatan website desa untuk kepentingan pemasaran juga mulai kami libatkan.

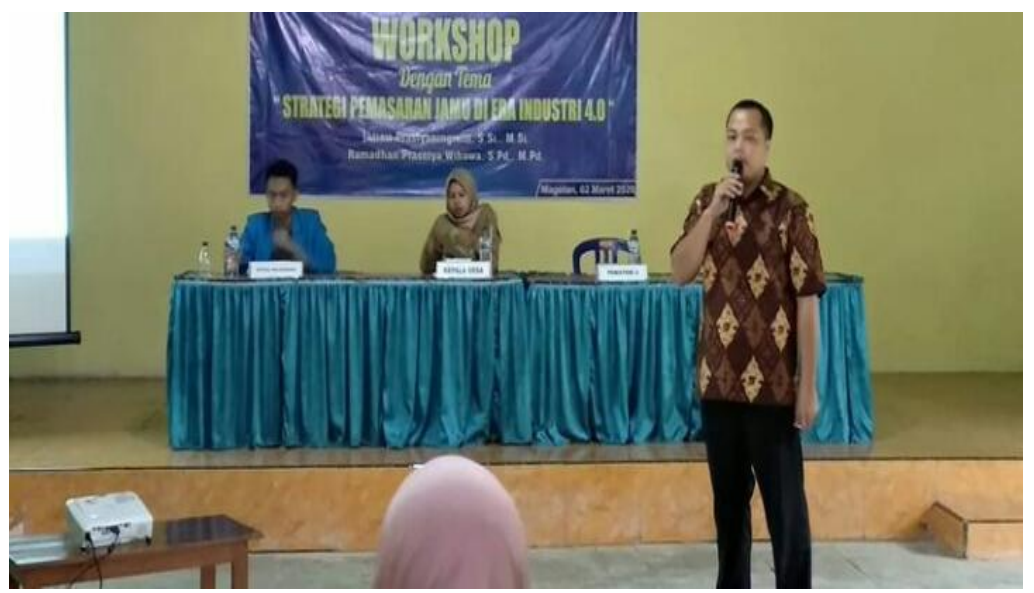

Gambar 5. Pelatihan Pemasaran Produk Jamu Joketro

\section{Dampak Kegiatan}

Dampak dari kegiatan Pengabdian Masyarakat yang sudah dilaksanakan ialah mampu bekerja sama dalam tim yaitu terjun langsung ke masyarakat. Mampu mengenalkan produk Jamu Tradisional ke ruang lingkup yang lebih luas dan memberikan identitas merek terhadap produk dengan cara membuatkan stiker, dan kemasan Jamu Tradisional Joketro yang lebih kekinian dan higienis. Dampak negatifnya terjadi kendala jaringan yang kurang bagus atau memadai dalam menggunakan media sosial. 


\section{SIMPULAN DAN SARAN}

Berdasarakan kegiatan yang sudah dilaksanakan melalui kegiatan pengabdian masyarakat yang dilaksanakan oleh tim pengabdian masyarakat yang bekerja sama dengan perangkat Desa Joketro, Kecamatan Parang Kabupaten Magetan serta dihadiri oleh ibu-ibu penjual jamu gendong di Desa Joketro dapat diambil simpulan: 1) Koordinasi dilaksanakan untuk memperoleh kesepakatan dan persetujuan izin kegiatan pengabdian masyarakat. 2) Pelaksaanan sosialisasi pembentukan kelompok jamu di Joketro berlangsung secara lancar yang dihadiri oleh ibu-ibu penjual jamu sejumlah 22 dengan terbentuk Kelompok Jamu Joketro. 3) Penyuluhan cara mengenalkan produk jamu mendapat apresiasi dari kepala desa melalui tindak lanjut akan diterapkan dengan cara mengajak masyarakat untuk minum jamu khas joketro. 4) Setelah dilaksanakan pelatihan, perangkat desa mengajak ibu-ibu penjual jamu gendong untuk menginovasikan olahan jamu yang lebih praktis, kemasan yang kekinian dan higienis, serta mulai memasarkan dan memperkenalkan jamu kepada masyarakat luas dalam kegiatan EXPO yang diselenggarakan oleh Kabupaten Magetan.

Saran yang dapat kami berikan untuk keberlanjutan program selanjutnya adalah agar produk Jamu Joketro semakin dikenal masyarakat perlu upaya pendampingan dari Dinas Kesehatan dan Pemerintah dalam membantu dalam pengurusan PIRT produk Jamu Joketro, serta untuk pengajuan Uji pembuatan Expo khusus untuk produk lokal daerah di Desa Joketro. Produk yang sudah ada selanjutnya bisa dipasarkan dalam marketplace agar produk lebih dikenal masyarakat luas.

\section{UCAPAN TERIMAKASIH}

Terimakasih kami ucapkan kepada Kepala Desa Joketro dan perangkatnya yang sudah memberikan izin, serta fasilitas sehingga kegiatan pengabdian masyarakat ini dapat berjalan dengan baik dan lancar. Ibu-ibu Penjual Jamu Gendong di Desa Joketro atas partisipasinya dalam kegiatan sosialisasi, penyuluhan, dan pelatihan, semoga terus berkembang, berinovasi menghasilkan produk jamu yang berkualitas. Terima kasih juga kami ucapkan kepada LPPM dan Mahasiswa yang membantu dalam pelaksanaan dan kelancaran kegiatan ini. 


\section{DAFTAR PUSTAKA}

Natadjaja, L., Tripoli, F., \& Wahyono, B. (2013). Ethnicity as Identity in Packaging Design of Traditional Medicine (Jamu) For Women (Doctoral dissertation, Petra Christian University).

Neubauer, I. L. (2012). TIME. Retrieved from Jamu: Why Isn't Indonesia's

Ancient System of Herbal Healing Better Known?,

http://content.time.com/time/world/article/0,8599,2107489,00.html. Diakses tanggal 29 Februari 2020.

Nissen, N., \& Evans, S. (2012). Exploring the practice and use of Western herbal medicine: perspectives from the social science literature. Journal of Herbal Medicine, 2(1), 6-15.

Prabawani, B. (2017). Jamu brand Indonesia: consumer preferences and segmentation. Archives of Business Research, 5(3).

Syafi'i, I. (2019). Pemasaran Jamu Menggunakan Kemasan Praktis Siap Minum dengan Branding Tren Masa Kini. Jurnal Pembelajaran Pemberdayaan Masyarakat (JP2M), 1(1), 35-41. 